\title{
Phase II trial of eribulin mesylate as a first- or second-line treatment for locally advanced or metastatic breast cancer: a multicenter, single-arm trial
}

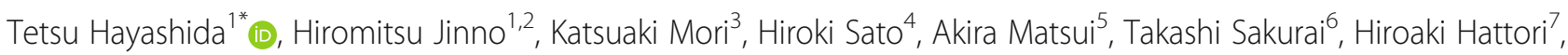
Shin Takayama ${ }^{8}$, Masahiro Wada ${ }^{9}$, Maiko Takahashi ${ }^{1}$, Hirohito Seki ${ }^{6}$, Tomoko Seki ${ }^{1}$, Aiko Nagayama ${ }^{5}$,

Akiko Matsumoto $^{2}$ and Yuko Kitagawa'

\begin{abstract}
Background: Eribulin mesylate is currently indicated as a sequential monotherapy to be administered after two chemotherapeutic regimens, including anthracycline and taxane treatments, for treatment of metastatic breast cancer. This open-label, multicenter phase II study was designed to evaluate the efficacy and safety of eribulin as a first- or second-line treatment for patients with metastatic breast cancer.

Methods: The primary objective was to determine the overall response rate. Secondary objectives were to evaluate progression-free survival and the safety profile. Patients were scheduled to receive eribulin mesylate $1.4 \mathrm{mg} / \mathrm{m}^{2}$ intravenously on days 1 and 8 of a 21-day cycle. Patients received the study treatment unless disease progression, unacceptable toxicity, or a request to discontinue from the patient and/or investigator eventuated.
\end{abstract}

Results: Between December 2012 and September 2015, 32 patients with metastatic breast cancer were enrolled at 10 participating clinical institutions in Japan, and toxicity and response rates were evaluated. The overall response rate was 43.8\% (95\% confidence interval [Cl] 26.5-61.0). The clinical benefit and tumor control rates were 56.3\% (95\% Cl 39.0-73.5) and 78.1\% (95\% Cl 63.8-92.5), respectively. Median progression-free survival was 8.3 months (95\% $\mathrm{Cl}$ 7.1-9.4). A subgroup analysis did not identify any factors affecting the efficacy of eribulin. The most common adverse events were neutropenia (71.9\%), alopecia (68.7\%), and peripheral neuropathy (46.9\%). As a first- or secondline therapy, eribulin showed sufficient efficacy for metastatic breast cancer compared with taxane and capecitabine treatment in previous clinical trials. The safety profile of eribulin was acceptable.

Conclusions: Eribulin may be another option for first-line chemotherapeutic regimens for metastatic breast cancer. Trial registrations: This trial was retrospectively registered at the University Hospital Medical Information Network (UMIN) Clinical Trial Registry (ID number: UMIN000010334).

Date of trial registration: April 1st, 2013.

Keywords: Breast cancer, Eribulin, Phase II trial

\footnotetext{
* Correspondence: tetsu@z7.keio.jp

${ }^{1}$ Department of Surgery, Keio University School of Medicine, 35

Shinanomachi., Shinjuku, Tokyo 160-8582, Japan

Full list of author information is available at the end of the article
}

(c) The Author(s). 2018 Open Access This article is distributed under the terms of the Creative Commons Attribution 4.0 International License (http://creativecommons.org/licenses/by/4.0/), which permits unrestricted use, distribution, and reproduction in any medium, provided you give appropriate credit to the original author(s) and the source, provide a link to the Creative Commons license, and indicate if changes were made. The Creative Commons Public Domain Dedication waiver (http://creativecommons.org/publicdomain/zero/1.0/) applies to the data made available in this article, unless otherwise stated. 


\section{Background}

Most cases of metastatic breast cancer are not curable and the strategy for treatment aims to extend life, suspend cancer progression, remove cancer-related symptoms, and improve quality of life. [1] Patients may derive sustained benefits from the administration of anthracyclines and taxanes, which are the standard chemotherapeutics for metastatic breast cancer [2]; however, ongoing research efforts aim to increase the number of available agents with more efficacy and less toxicity to improve treatment strategies.

Eribulin mesylate (eribulin) is a non-taxane, microtubule dynamics inhibitor belonging to the halichondrin class of antineoplastic agents. The growth phase of microtubules is effectively suppressed by eribulin without affecting the shortening phase, and eribulin isolates tubulin into non-productive aggregates. [3] In a global phase III trial, a survival benefit was confirmed in women with heavily pretreated advanced breast cancer assigned to eribulin versus a control arm of patients receiving the physician's choice of treatment (hazard ratio (HR) 0.81, 95\% confidence interval [CI], 0.66-0.99; $P=$ 0.041). [4] Eribulin also demonstrated a positive survival benefit compared with capecitabine in another phase III trial; however, this improvement did not meet the set criteria for statistical significance. [5] Moreover, a pooled analysis of the above-mentioned phase III studies demonstrated that eribulin-treated patients had a significantly extended overall survival (OS). [6]

Based on results from these studies, in the United States eribulin is currently indicated in metastatic breast cancer as a sequential monotherapy to be administered after two chemotherapeutic regimens, including anthracycline and taxane treatments. In Japan, however, eribulin has been approved for use for patients with metastatic breast cancer regardless of the number of pretreatment chemotherapeutic regimens.

The American Society of Clinical Oncology clinical practice guidelines suggest that no clear evidence exists for the superiority of one specific drug or regimen for first- and second-line treatment of patients with metastatic breast cancer. The guideline also recommends that previous therapy and differential toxicity should be considered for treatment selection, although anthracycline and taxanes have the strongest evidence for efficacy. [7] Therefore, eribulin, which has been proven effective and safe in heavily pretreated patients, is a possible candidate as an upfront agent for metastatic breast cancer. In this context, we conducted this single-arm, multicenter phase II trial to investigate the efficacy and safety of eribulin for first- and second-line treatment, which may provide another option for upfront chemotherapeutic regimens for patients with metastatic breast cancer.

\section{Methods}

\section{Study design}

This open-label, multicenter phase II study was designed to evaluate the efficacy and safety of eribulin as a firstor second-line treatment for patients with metastatic breast cancer. The primary objective was to determine the overall response rate (ORR). Secondary objectives were to evaluate progression-free survival (PFS), the clinical benefit rate (CBR), the tumor control rate, the objective response rates for patient subgroups, and the safety profile of eribulin. CBR was defined as the proportion of patients with a complete response (CR) or a partial response (PR), or with stable disease at 6 months. The tumor control rate was defined as the proportion of patients who achieved a CR or PR, or with stable disease. Subgroup analyses were performed based on receptor status, metastatic site, and dose reduction during treatment.

\section{Eligibility criteria}

Women who met the following criteria were eligible for inclusion: histologically or cytologically confirmed recurrent or metastatic adenocarcinoma of the breast with at least 1 measurable lesion, according to the Response Evaluation Criteria in Solid Tumors (RECIST) version 1.1.; an Eastern Cooperative Oncology Group (ECOG) performance status score of 0,1 , or 2; a life expectancy of more than 12 weeks; up to one prior chemotherapy regimen for advanced and/or metastatic disease; a normal electrocardiogram; and laboratory cut-off values, as follows: neutrophil count $\geq 1.5 \times 10^{9} / \mathrm{L}$, platelet count $\geq 100 \times 10^{9} / \mathrm{L}$, hemoglobin level $\geq 9.0 \mathrm{~g} / \mathrm{dL}$, serum bilirubin level $<2.0 \times$ the upper limit of the normal level, and aspartate aminotransferase (AST), alanine aminotransferase (ALT), and alkaline phosphatase levels $<2.5 \times$ the upper limit of the normal level, and a serum creatinine level $<1.5 \mathrm{mg} / \mathrm{dL}$. Patients were excluded if they had prior eribulin treatment or had been diagnosed with a serious concomitant illness such as uncontrolled diabetes, severe cardiovascular disease, interstitial pneumonia, lung fibrosis, or active concomitant malignancy. Pregnant or lactating women were also excluded.

\section{Treatment plan}

Patients were scheduled to receive eribulin mesylate $1.4 \mathrm{mg} / \mathrm{m}^{2}$ intravenously on days 1 and 8 in each 21-day cycle. Patients received study treatment unless disease progression, unacceptable toxicity, or a request to discontinue from the patient and/or the investigator eventuated. Toxicities were evaluated according to the National Cancer Institute Common Terminology Criteria for Adverse Events (CTCAE version 4) throughout treatment with eribulin. Treatment could be postponed for a maximum of 3 weeks for severe toxicity. Dose reductions of 
eribulin from $1.4 \mathrm{mg} / \mathrm{m}^{2}$ to $1.1 \mathrm{mg} / \mathrm{m}^{2}$ and from $1.1 \mathrm{mg} /$ $\mathrm{m}^{2}$ to $0.7 \mathrm{mg} / \mathrm{m}^{2}$ were permitted in cases of febrile neutropenia and grade 3 or 4 non-hematological toxicities, respectively. G-CSF was appropriately used according to the guideline made by Japan Society of Clinical Oncology.

\section{Response evaluation}

Tumor response was determined according to RECIST version 1.1 and had to be confirmed after every 3 cycles using spiral computed tomography or magnetic resonance imaging. When a symptom suggesting bone metastasis was observed, bone scintigraphy was performed. Patients who discontinued treatment due to adverse events (AEs) prior to the first evaluation were categorized as not evaluated (NE). After first observation of a $\mathrm{CR}$ or a PR, tumor response was confirmed at a second assessment 4 weeks later. Time to progression was determined as the interval from the start of treatment to the date of the documented tumor progression, or the date of death from any cause if the patient died prior to documentation of disease progression.

\section{Statistical analyses}

Efficacy analyses were performed on the intention-to-treat population. The primary objective of this study was to show adequate activity of eribulin treatment measured using objective response rates. For an appropriate sample size calculation and using a two-sample t-test to test the null hypothesis of a true response rate of $20 \%$ against the alternative hypothesis of a true response rate of almost $40 \%, 32$ assessable patients had to be included ( $\alpha=0.05 ; \beta=0.8)$. Therefore, we set a final sample size at 35 patients. Tumor assessments were obtained from an investigator radiology review.

\section{Results}

\section{Patient characteristics}

Between December 2012 and September 2015, 35 patients with metastatic breast cancer were assigned to our clinical trial at 10 participating clinical institutions in Japan. Two patients did not meet the criteria and one patient withdrew consent prior to treatment; therefore, 32 patients were enrolled and evaluated for toxicity and response rates. Baseline patient demographics and disease characteristics are shown in Table 1. Twenty-two (68.8\%) patients received eribulin as a first-line chemotherapy for advanced disease. Five patients (15.6\%) had received taxane and 5 patients $(15.6 \%)$ had received oral 5-FU (capecitabine or S-1) prior to eribulin treatment.

\section{Efficacy}

At the time of this analysis, a total of 32 patients were assessable for efficacy. The ORR was 43.8\% (95\% CI 26.5-61.0) (Table 2). CBR and tumor control rates were
Table 1 Patient demographics and disease characteristics

\begin{tabular}{|c|c|c|}
\hline & No. of patients & $\%$ \\
\hline \multicolumn{3}{|l|}{ Age, years } \\
\hline Median & 66 & \\
\hline Range & $39-82$ & \\
\hline \multicolumn{3}{|l|}{ ECOG performance status } \\
\hline 0 & 25 & 78.1 \\
\hline 1 & 5 & 15.6 \\
\hline 2 & 2 & 6.3 \\
\hline (Neo-)adjuvant chemotherapy & 22 & 68.7 \\
\hline Anthracycline & 7 & 21.9 \\
\hline Taxane & 2 & 6.3 \\
\hline Anthracycline $+\operatorname{taxan}$ & 11 & 34.4 \\
\hline Oral 5FU & 1 & 3.1 \\
\hline CMF & 1 & 3.1 \\
\hline Adjuvant endocrine therapy & 14 & 43.7 \\
\hline Prior endocrine therapy for advanced disease & 15 & 46.9 \\
\hline \multicolumn{3}{|c|}{ No. of prior chemotherapy regimens for advanced disease } \\
\hline 0 & 22 & 68.8 \\
\hline 1 & 10 & 31.3 \\
\hline Taxan & 5 & 15.6 \\
\hline Oral 5FU (capecitabine or S-1) & 5 & 15.6 \\
\hline ER-postive & 19 & 59.4 \\
\hline PgR-positive & 18 & 56.3 \\
\hline HER2-positive & 1 & 3.1 \\
\hline Triple negatve & 11 & 33.3 \\
\hline \multicolumn{3}{|l|}{ Metastatic site } \\
\hline Liver & 14 & 43.8 \\
\hline Lung & 14 & 43.8 \\
\hline Brain & 0 & 0 \\
\hline Bone & 13 & 40.6 \\
\hline Skin & 8 & 25 \\
\hline Other & 14 & 43.8 \\
\hline \multicolumn{3}{|l|}{ No of organs involved } \\
\hline 1 & 9 & 28.1 \\
\hline 2 & 13 & 40.6 \\
\hline 3 & 5 & 15.6 \\
\hline 4 & 5 & 15.6 \\
\hline \multicolumn{3}{|l|}{ Site of disease } \\
\hline Viceral & 23 & 71.9 \\
\hline
\end{tabular}

Abbreviations: ECOG Eastrern cooperative oncology group, $E R$ estrogen receptor, $P g R$ progesterone receptor, HER2 human epidermal growth factor receptor 2

achieved in 56.3\% (95\% CI 39.0-73.5) and 78.1\% (95\% CI 63.8-92.5) of patients, respectively. The maximum change in tumor size for each patient is shown in Fig. 1. The median PFS was 8.3 months (95\% CI 7.1-9.4) 
Table 2 Efficacy outcomes

\begin{tabular}{llll}
\hline & No. of patients & $\%$ & \\
\hline All assessable patients & 32 & $95 \% \mathrm{Cl}$ \\
$\mathrm{CR}$ & 3 & 34.4 \\
$\mathrm{PR}$ & 11 & 34.4 \\
$\mathrm{SD}$ & 11 & 12.5 \\
$\mathrm{PD}$ & 4 & 9.4 \\
$\mathrm{NE}$ & 3 & 43.8 & (26.5-61.0) \\
Overall response $(\mathrm{CR}+\mathrm{PR})$ & 14 & 56.3 & $(39.0-73.5)$ \\
Clinical benefit rate $(\mathrm{CR}+\mathrm{PR}+\mathrm{SD} \geqq 6$ months) & 18 & 78.1 & (63.8-92.5) \\
Tumor control rate $(C R+P R+S D)$ & 25 & &
\end{tabular}

(Fig. 2). Subgroup analysis did not identify any factor affecting the efficacy of eribulin with statistical significance (Table 3).

\section{Safety}

All patients experienced a treatment-related adverse event (AE). The most common AEs were neutropenia (71.9\%), alopecia (68.7\%), and peripheral neuropathy (46.9\%) (Table 4). Twelve patients experienced a SAE: 7 grade 4 neutropenia, 1 febrile neutropenia, 4 grade 3 fatigue.

Treatment for AEs led to dose reductions for 14 patients $(43.8 \%)$, and these dose reductions were most commonly due to neutropenia and peripheral neuropathy. Two patients (6.2\%) discontinued eribulin treatment prior to the first evaluation. One patient discontinued eribulin after 2 cycles of treatment due to grade 3 fatigue. Another patient was discontinued after a cycle also due to grade 3 fatigue. A patient died because of aggressive disease progression after 2 cycles of treatment.

\section{Discussion}

This single-arm, multicenter phase II study, assessing first- and second-line treatment with eribulin monotherapy for advanced breast cancer, found a $43.8 \%$ ORR and a median PFS of 8.3 months. These outcomes are not inferior to several randomized control studies using paclitaxel monotherapy for advanced breast cancer in the control arm, for which the reported range of ORR is between 21.2 and $26.2 \%$. [3, 8] In some situations, oral 5-FU agents may be selected as upfront treatment for advanced breast cancer. First-line capecitabine monotherapy has an ORR of $22 \%$ and a PFS of 6 months, [9] which is consistent with the findings of the current trial. Miller et al. reported that patients $(n=346)$ who received $90 \mathrm{mg} / \mathrm{m}^{2}$ of paclitaxel on days 1,8 , and 15 of every 28-day cycle as first-line chemotherapy had a 21.2\% ORR and a PFS of 5.9 months. [8] In this study,

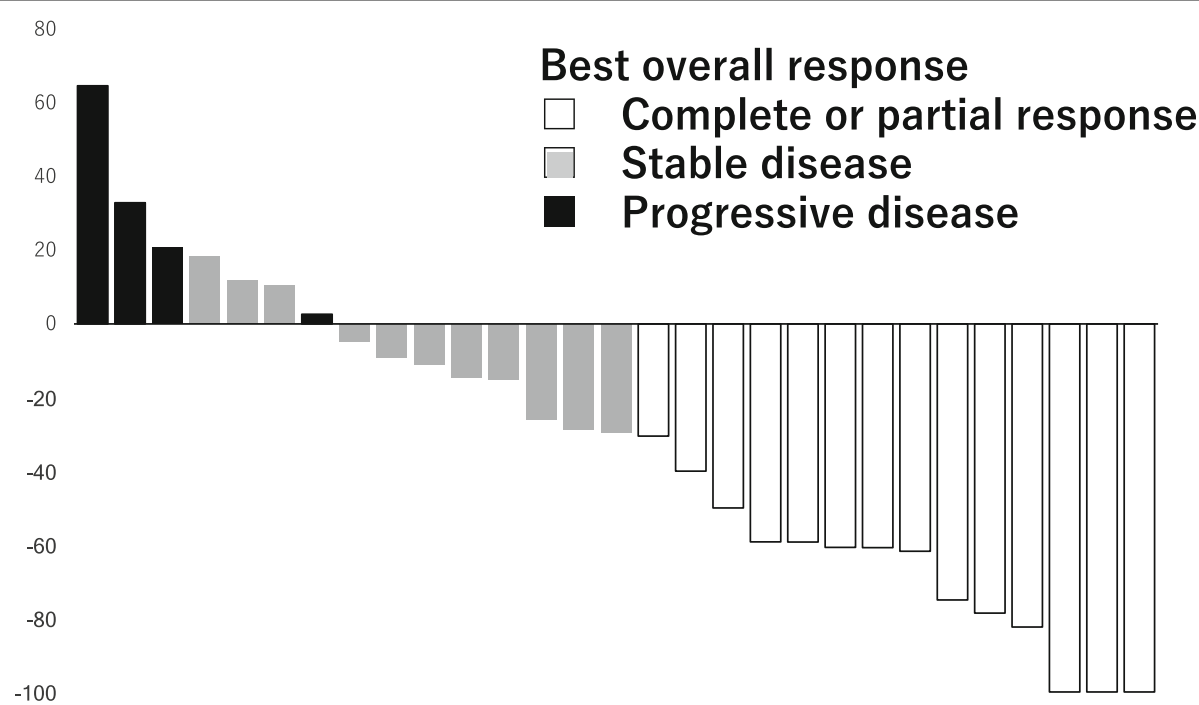

Fig. 1 Waterfall graphs of percentage change in the total sum of target lesion diameters from baseline to postbaseline nadir (RECIST v1.1) 


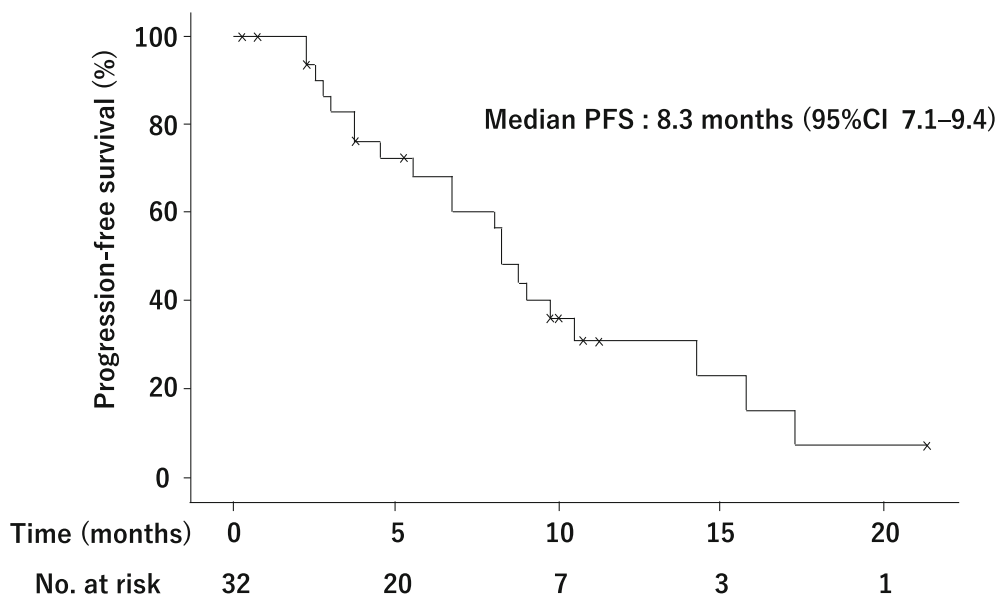

Fig. 2 Kaplan-Meier plot of progression-free survival

adding bevacizumab to paclitaxel improved the ORR to 36.9\% and the PFS to 11.8 months; however, OS was similar to paclitaxel monotherapy. On the other hand, a pooled analysis of the EMBRACE and the 301 trials confirmed that eribulin-treated patients had a significantly extended OS. [6]

Recent preclinical studies have provided important information on how eribulin prolongs OS. Yoshida et al. reported that treatment of triple negative breast cancer cells with eribulin led to morphological and molecular changes consistent with transition of a mesenchymal to an epithelial phenotype through inhibition of SMAD2 and SMAD3 phosphorylation. [10] Several studies have also suggested that eribulin changes microenvironmental vascular networks around tumors. Eribulin, but not paclitaxel, showed strong efficacy as an antivascular agent that affected pericyte-driven angiogenesis. [11] Another study revealed that eribulin-induced remodeling of tumor vasculature leading to a more functional microenvironment that may reduce the aggressiveness of tumors. [11] Eribulin treatment also increased tumor oxygen saturation and decreased the plasma concentration of TGF-beta1 leading to a favorable anti-angiogenic effect. [12] These capabilities of eribulin, demonstrated through preclinical studies to reverse the aggressive characteristics related to both cellular phenotype and microenvironment, may be contributing to its clinical benefits. Therefore, the strategy of upfront treatment with eribulin may be able to reduce the aggressiveness of tumors, which contributes to the efficacy of later

Table 3 Objective response rates for over all population and subgroups of patients

\begin{tabular}{|c|c|c|c|c|}
\hline & $\mathrm{N}$ & Overall response rate (\%) & Clinical benefit rate (\%) & Median PFS $(95 \% \mathrm{Cl})$, months \\
\hline Overall & 32 & 43.8 & 56.3 & $8.3(7.1-9.4)$ \\
\hline \multicolumn{5}{|c|}{ Hormone receptor status } \\
\hline $\mathrm{HR}(-)$ & 12 & 33.3 & 41.7 & $5.5(0-11.5)$ \\
\hline $\mathrm{HR}(+)$ & 20 & 50 & 65 & $8.8(6.46-11.0)$ \\
\hline \multicolumn{5}{|c|}{ No. of prior chemotherapy } \\
\hline 0 & 22 & 50 & 54.5 & $8.8(7.4-10.1)$ \\
\hline 1 & 10 & 30 & 70 & $8.3(3.7-12.8)$ \\
\hline \multicolumn{5}{|l|}{ Metastatic site } \\
\hline Visceral & 23 & 43.5 & 60.9 & $8.3(7.2-9.3)$ \\
\hline Non-visceral & 9 & 44.4 & 44.4 & $9.0(4.2-13.8)$ \\
\hline \multicolumn{5}{|c|}{ Dose reduction during treatment } \\
\hline No reduction & 18 & 33.3 & 50 & $8.8(3.9-13.6)$ \\
\hline Reduction & 14 & 57.1 & 64.3 & $8.3(7.8-8.7)$ \\
\hline \multicolumn{5}{|c|}{ Hormone receptor status } \\
\hline Triple negative & 11 & 36.4 & 36.4 & $5.5(1.3-9.7)$ \\
\hline Other & 21 & 47.6 & 71.4 & $8.8(7.0-10.5)$ \\
\hline
\end{tabular}


Table 4 Treatment-related adverse events

\begin{tabular}{llll}
\hline & Any grade & Grade 3 & Grade 4 \\
\hline Hematologic & $23(71.9)$ & $6(18.8)$ & $7(21.9)$ \\
Neutropenia & $7(21.9)$ & $1(3.1)$ & 0 \\
Anemia & $5(15.6)$ & $2(6.3)$ & 0 \\
Thrombopenia & $1(3.1)$ & $1(3.1)$ & 0 \\
Febrile Neutropenia & & & \\
Nonhematologic & $16(50.0)$ & $4(12.5)$ & 0 \\
Fatigue & $22(68.7)$ & $\mathrm{N} / \mathrm{A}$ & \\
Alopecia & $15(46.9)$ & $4(12.5)$ & 0 \\
Peripheral neuropathy & $4(12.6)$ & 0 & 0 \\
Arthralgia & $7(21.9)$ & $1(3.1)$ & 0 \\
Constipation & $2(6.2)$ & 0 & 0 \\
Diarrhea & $8(25.0)$ & 0 & 0 \\
Nausea & $1(3.1)$ & 0 & 0 \\
Vomitting & $9(28.1)$ & $2(6.3)$ & 0 \\
Stomatitis & & &
\end{tabular}

management with another form of chemotherapy, and to prolonging patient survival.

McIntyre et al. and Takashima et al. each conducted and reported phase II studies to investigate the efficacy and safety of first-line eribulin treatment for metastatic breast cancer, and reported ORRs of 29 and 54.3\%, respectively. [13, 14] Despite including second-line treatment in our study, the ORR was $43.8 \%$ and this result is similar to previous first-line trials. Moreover, the PFS in this study was superior to previous studies; however, the difference may be due to bias in relation to the study design. Radiographic evaluation was undertaken after every 3 cycles of eribulin treatment in this study, but an evaluation was conducted after every 2 cycles of eribulin treatment in the first-line trials, suggesting that the PFS in this study might be overestimated. However, in an actual clinical situation, assessments using computed tomography and bone scintigraphy might not be conducted every 6 weeks. Therefore, it is likely that our data may be relatively close to a real-world situation.

The safety profile of eribulin in upfront treatment was similar to that identified in previous studies. [4, $5,13,14]$ The most frequent non-hematologic AEs of any grade were fatigue (50\%), alopecia (68.7\%), and peripheral neuropathy $(46.9 \%)$. Neutropenia was the most frequent grade $3(18.8 \%)$ or $4(21.9 \%)$ AE. Febrile neutropenia was reported only in one patient. Dose reductions were most commonly due to neutropenia and peripheral neuropathy; however, the efficacy of eribulin did not change in the subgroup analysis. Therefore, patients may have some clinical benefit from continuous treatment with eribulin regardless of dose intensity.

\section{Conclusion}

Overall, as a first- or second-line therapy, eribulin showed comparable efficacy for metastatic breast cancer in comparison with a single treatment of taxane and oral 5-FU as a first-line therapy as shown in previous clinical trials. Eribulin also demonstrated acceptable safety and tolerability. These results suggest that eribulin may have clinical benefits as an upfront chemotherapeutic regimen for metastatic breast cancer patients.

\section{Abbreviations \\ AE: Adverse event; ALT: Alanine aminotransferase; AST: Aspartate aminotransferase; CR: Complete response; CTCAE: National Cancer Institute Common Terminology Criteria for Adverse Events; ECOG: Eastern Cooperative Oncology Group; ORR: Overall response rate; OS: Overall survival; PFS: Progression-free survival; PR: Partial response; RECIST: Response Evaluation Criteria in Solid Tumors}

\section{Acknowledgments}

We would like to thank the patients, their families, the medical staff, and the investigators who were participating in this study.

Funding

The authors declare that no funding was received for this study.

\section{Availability of data and materials}

The datasets analyzed during the current study are available from the corresponding author upon reasonable request.

\section{Authors' contributions}

$\mathrm{HTe}, \mathrm{JHi}$, and $\mathrm{KYu}$ contributed to conception and design of the trial. MKa, SHi, MAk, STa, HHi, TSh, WMa, TMa, SHi, STo, NAi, and MAk contributed to acquisition of data or analysis and interpretation. HTe did the statistical analysis and contributed together with $\mathrm{JHi}$ to data analysis and interpretation. HTe drafted the manuscript. All authors critically revised the manuscript for important intellectual content and approved the final version to be published. All authors agreed to be accountable for all aspects of the work in ensuring that questions related to the accuracy or integrity in any part of the work are appropriately investigated and resolved.

\section{Ethics approval and consent to participate}

The study was undertaken in accordance with the Declaration of Helsinki and the study protocol received local approval of the Ethic Committee of Keio University Hospital. Initial approval was obtained on November 27, 2012. Local ethics committees approved the studies in the participating facilities (the Ethic Committee of National Hospital Organization Tokyo Medical Center, the Ethic Committee of Hino Municipal Hospital, the Ethic Committee of Japanese Red Cross Medical Center, the Ethic Committee of Japan Community of Health Care Organization, the Ethic Committee of Federation of National Public Service Personnel Mutual Aid Associations, the Ethic Committee of Tokyo Dental College, the Ethic Committee of Kitasato University School of Medicine, the Ethic Committee of Teikyo University Hospital, the Ethic Committee of Inagi Municipal Hospital). Written informed consent was obtained from all patients prior to screening assessments or enrolment.

\section{Consent for publication \\ Not applicable.}

\section{Competing interests}

T. Hayashida has received grants and/or speaker's honoraria from Daiichi Sankyo, Eisai, Novartis Pharma, Takeda, AstraZeneca, Chugai within the past three years. Y. Kitagawa has received grants and/or speaker's honoraria from Daiichi Sankyo, Eisai, Eli Lilly, GlaxoSmithKline, Novartis Pharma, Chugai, Pfizer, Shionogi, Takeda, Otsuka Pharmaceutical within the past three years. Hiromitsu Jinno has received grants and/or speaker's honoraria from Daiichi Sankyo, Eisai, Novartis Pharma, Chugai, Takeda, Astra Zeneca within the past three years. A. Nagayama owns stock options of Chugai. A. Nagayama's immediate family member has a leadership position of Chugai and Roche. 


\section{Publisher's Note}

Springer Nature remains neutral with regard to jurisdictional claims in published maps and institutional affiliations.

\section{Author details}

'Department of Surgery, Keio University School of Medicine, 35

Shinanomachi., Shinjuku, Tokyo 160-8582, Japan. ${ }^{2}$ Department of Surgery, Teikyo University School of Medicine, Tokyo, Japan. ${ }^{3}$ Department of Surgery, Hino Municipal Hospital, Tokyo, Japan. ${ }^{4}$ Department of Surgery, Mito Red Cross Hospital, Ibaraki, Japan. ${ }^{5}$ Department of Surgery, National Hospital Organization Tokyo Medical Center, Tokyo, Japan. ${ }^{6}$ Division of Surgery, JCHO Saitama Medical Center, Saitama, Japan. ${ }^{7}$ Department of Surgery, Federation of National Public Service Personnel Mutual Aid Associations, Tachikawa Hospital, Tokyo, Japan. ${ }^{8}$ Department of surgery, Tokyo Dental College Ichikawa General Hospital, Tokyo, Japan. ${ }^{9}$ Department of Surgery, Sanokousei general hospital, Tochigi, Japan.

Received: 19 August 2017 Accepted: 22 June 2018

Published online: 28 June 2018

\section{References}

1. Goldhirsch A, Winer EP, Coates AS, Gelber RD, Piccart-Gebhart M, Thurlimann B, Senn HJ. Personalizing the treatment of women with early breast cancer: highlights of the St Gallen international expert consensus on the primary therapy of early breast Cancer 2013. Ann Oncol. 2013;24(9): 2206-23.

2. Colozza M, de Azambuja E, Personeni N, Lebrun F, Piccart MJ, Cardoso F. Achievements in systemic therapies in the pregenomic era in metastatic breast cancer. Oncologist. 2007;12(3):253-70.

3. Jordan MA, Kamath K, Manna T, Okouneva T, Miller HP, Davis C, Littlefield BA, Wilson $L$. The primary antimitotic mechanism of action of the synthetic halichondrin E7389 is suppression of microtubule growth. Mol Cancer Ther. 2005:4(7):1086-95.

4. Cortes J, O'Shaughnessy J, Loesch D, Blum JL, Vahdat LT, Petrakova K, Chollet P, Manikas A, Dieras V, Delozier T, et al. Eribulin monotherapy versus treatment of physician's choice in patients with metastatic breast cancer (EMBRACE): a phase 3 open-label randomised study. Lancet. 2011;377(9769): 914-23.

5. Kaufman PA, Awada A, Twelves C, Yelle L, Perez EA, Velikova G, Olivo MS, He Y, Dutcus CE, Cortes J. Phase III open-label randomized study of eribulin mesylate versus capecitabine in patients with locally advanced or metastatic breast cancer previously treated with an anthracycline and a taxane. J Clin Oncol. 2015;33(6):594-601.

6. Twelves C, Cortes J, Vahdat L, Olivo M, He Y, Kaufman PA, Awada A. Efficacy of eribulin in women with metastatic breast cancer: a pooled analysis of two phase 3 studies. Breast Cancer Res Treat. 2014;148(3):553-61.

7. Partridge AH, Rumble RB, Carey LA, Come SE, Davidson NE, Di Leo A, Gralow J, Hortobagyi GN, Moy B, Yee D et al: Chemotherapy and targeted therapy for women with human epidermal growth factor receptor 2negative (or unknown) advanced breast cancer: American Society of Clinical Oncology clinical practice guideline. J Clin Oncol 2014, 32(29):3307-3329.

8. Miller K, Wang M, Gralow J, Dickler M, Cobleigh M, Perez EA, Shenkier T, Cella D, Davidson NE. Paclitaxel plus bevacizumab versus paclitaxel alone for metastatic breast cancer. N Engl J Med. 2007;357(26):2666-76.

9. Stockler MR, Harvey VJ, Francis PA, Byrne MJ, Ackland SP, Fitzharris B, Van Hazel G, Wilcken NR, Grimison PS, Nowak AK, et al. Capecitabine versus classical cyclophosphamide, methotrexate, and fluorouracil as first-line chemotherapy for advanced breast cancer. J Clin Oncol. 2011; 29(34):4498-504.

10. Yoshida T, Ozawa Y, Kimura T, Sato Y, Kuznetsov G, Xu S, Uesugi M, Agoulnik S, Taylor N, Funahashi Y, et al. Eribulin mesilate suppresses experimental metastasis of breast cancer cells by reversing phenotype from epithelial-mesenchymal transition (EMT) to mesenchymal-epithelial transition (MET) states. Br J Cancer. 2014;110(6):1497-505.

11. Agoulnik SI, Kawano S, Taylor N, Oestreicher J, Matsui J, Chow J, Oda Y, Funahashi Y. Eribulin mesylate exerts specific gene expression changes in pericytes and shortens pericyte-driven capillary network in vitro. Vasc Cell. 2014;6(1):3.

12. Ueda S, Saeki T, Takeuchi H, Shigekawa T, Yamane T, Kuji I, Osaki A. In vivo imaging of eribulin-induced reoxygenation in advanced breast cancer patients: a comparison to bevacizumab. Br J Cancer. 2016;114(11):1212-8.
13. Mclntyre K, O'Shaughnessy J, Schwartzberg L, Gluck S, Berrak E, Song JX, Cox D, Vahdat LT. Phase 2 study of eribulin mesylate as first-line therapy for locally recurrent or metastatic human epidermal growth factor receptor 2negative breast cancer. Breast Cancer Res Treat. 2014;146(2):321-8.

14. Takashima T, Tokunaga S, Tei S, Nishimura S, Kawajiri H, Kashiwagi S, Yamagata S, Noda S, Nishimori T, Mizuyama Y, et al. A phase II, multicenter, single-arm trial of eribulin as first-line chemotherapy for HER2-negative locally advanced or metastatic breast cancer. Springerplus. 2016:5:164.

\section{Ready to submit your research? Choose BMC and benefit from:}

- fast, convenient online submission

- thorough peer review by experienced researchers in your field

- rapid publication on acceptance

- support for research data, including large and complex data types

- gold Open Access which fosters wider collaboration and increased citations

- maximum visibility for your research: over $100 \mathrm{M}$ website views per year

At BMC, research is always in progress.

Learn more biomedcentral.com/submissions 